\title{
A Micro-Scale Cyclone-Wind Turbine for Rooftop Ventilator
}

\author{
Unggul Wibawa, Akhmad Frandicahya Permadi, Rini Nur Hasanah \\ Electrical Engineering Department, Faculty of Engineering, Brawijaya University \\ Jalan MT Haryono 167 Malang 65145 Indonesia, telp/fax: +62 341 554166/551430
}

\begin{tabular}{l}
\hline \hline Article Info \\
\hline Article history: \\
Received Mar 1, 2018 \\
Revised Apr 20, 2018 \\
Accepted May 1, 2018 \\
\hline
\end{tabular}

\section{Keywords:}

Abandoned energy

Cyclone turbine

Rooftop ventilator

Small energy

Wind power

\begin{abstract}
This paper analyzes the model of a cyclone-turbine for a micro-scale windpower system being motivated by an idea to harvest the abandoned energy from rooftop ventilators. The system under consideration has been equipped with a battery to form a wind-battery power system. Data obtained from a wind site observation have been used to calculate the potentially generated power and efficiency, as well as the mechanical and electrical designs to extract the energy. The design has been explored to obtain the best efficiency of the cyclone-turbine model. The impact of wind-speed variation on the resulted system output has been investigated during the charging process of battery. The conclusion emphasizes the relationship between the output power and the range values of the resulted current and voltage, as well as the optimum wind speed-range of the cyclone-turbine operation.
\end{abstract}

Copyright (C) 2018 Institute of Advanced Engineering and Science. All rights reserved.

\section{Corresponding Author:}

Unggul Wibawa,

Electrical Engineering Department, Faculty of Engineering, Brawijaya University

Jalan MT Haryono 167 Malang 65145 Indonesia, telp/fax: +62 341 554166/551430

Email: rini.hasanah@ub.ac.id

\section{INTRODUCTION}

Cyclone turbine, also known as rooftop ventilator, is generally placed on the roof of industrial buildings, workshops, and some warehouses to provide a ventilation system. They do not need any electrical energy to work. They are functioning by taking advantage of the air flow on the top of the roof or by sucking the lifting hot air coming from the inside of the building under the roof and letting pass through the air toward outside of the building to maintain the temperature [1]. Being maintenance-free, it is an eco-friendly green product, helping in reducing the carbon footprint and contributing to energy savings [2].

A wind turbine on the other side is working by capturing the wind's kinetic energy using a rotor consisting of two or more blades mechanically coupled to a generator [3-5]. Two distinct configurations of turbine design being available in the market are the horizontal-axis wind turbine (HAWT) configuration and the vertical-axis wind turbine (VAWT) configuration [6].

A modified cyclone turbine can be categorized into the VAWT type. It spins vertically when capturing the kinetic energy of the wind. It operates in the same basic manner and also has the same shaft position and blade form as a VAWT does [7]. By re-arranging the positions of rotor and stator, a very low starting torque to minimize the self-starting speed of a turbine can be obtained [8]. Torasa, et al. developed a model for power generation using rooftop ventilator by mounting a DC generator inside the ventilator geared to the central shaft [9].

This paper discusses the model of a cyclone turbine for a micro-scale wind-battery power system. It has been motivated by the idea to harvest the abandoned small energy from rooftop ventilators. The cyclone turbine converts the wind kinetic energy to electricity. A battery has been taken into account considering the practical usage of the generated electricity. The resulted free electricity needs to be equipped with a battery charger to allow the process of battery charging. It is also useful to ensure no back-flow current if the roof ventilator is not functioning. An inverter may be needed if it is used to supply an AC load. 


\section{THE PROPOSED DESIGN AND TESTING METHOD}

The proposed construction of the cyclone-turbine for wind power generation consists of the mechanical system and electrical system as shown in Figure 1.

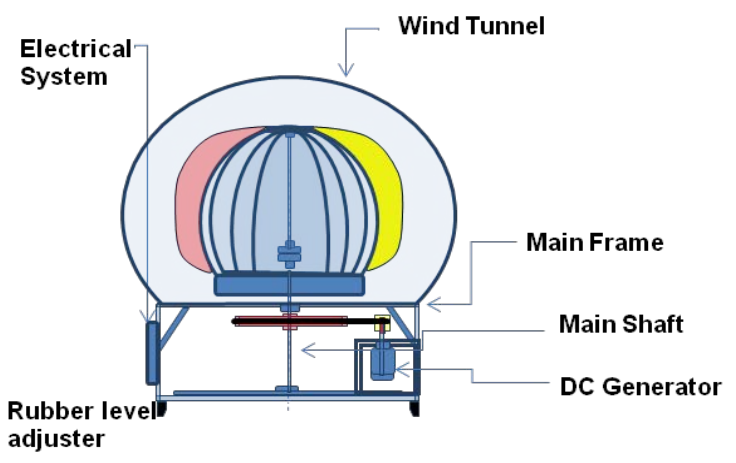

Figure 1. The cyclone turbine construction

\subsection{Mechanical System Design}

The initial cyclone-turbine used was of the type L45 Split available in the market. It has the dimension ( $\mathrm{LxHxW}$ ) of $75 \times 68 \times 68 \mathrm{~cm}^{3}, 28$ wind-blades and the suction capacity of $42.39 \mathrm{~m}^{3} / \mathrm{min}$. As this type of turbine possesses an inherent low starting torque, it was modified by adding some fins. Eight extra fins have been added to increase the spin, cross-sectional area and efficiency. Each of the twenty-eight original blades has the surface are of $0.03 \mathrm{~m} 2$, whereas each of the eight additional fins has the surface are of $0.054 \mathrm{~m} 2$. The dimensions of the original blade and the additional fins are shown in Figure 2 (left), whereas the resulted modification is given in Figure 2 (right).
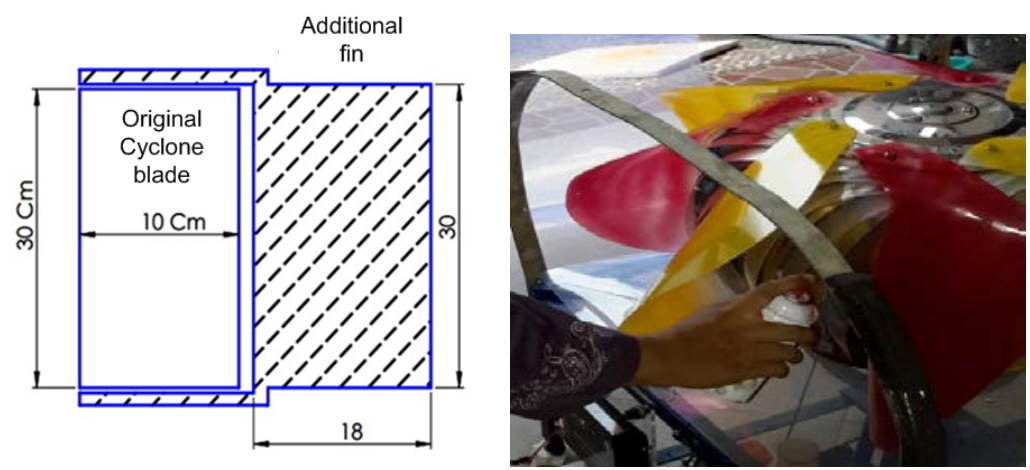

Figure 2. The mechanical system design: additional fins dimension (left) and the resulted turbine blade modification (right)

The generated power can be obtained based on the wind power generation formula as following:

$$
P(\text { watt })=(1 / 2) \times A \times \rho_{\mathrm{a}} \times v^{3}
$$

As can be observed from Equation 1, the increase in speed of spin $(v)$ and cross-sectional area $(A)$ causes the increase in the generated power $(P)$ [10-12].

\subsection{Electrical System Design}

The diagram of the electrical system design is given in Figure 3. The boost converter is used to increase the voltage of the source (dc generator), so that the necessary voltage can be obtained accordingly [13-14]. The boost converter being used during the testing was the XL6009 type which has the input voltage range of $3-32 \mathrm{~V}$ and the output voltage range of $5-35 \mathrm{~V}$. 
The specification of the generator used was: DC generator, 50W, $350 \mathrm{rpm}, 12-24 \mathrm{VDC}$ of output voltage, $70 \mathrm{~mm}$ of diameter, $110 \mathrm{~m}$ of height, and $8 \mathrm{~mm}$ of shaft diameter.

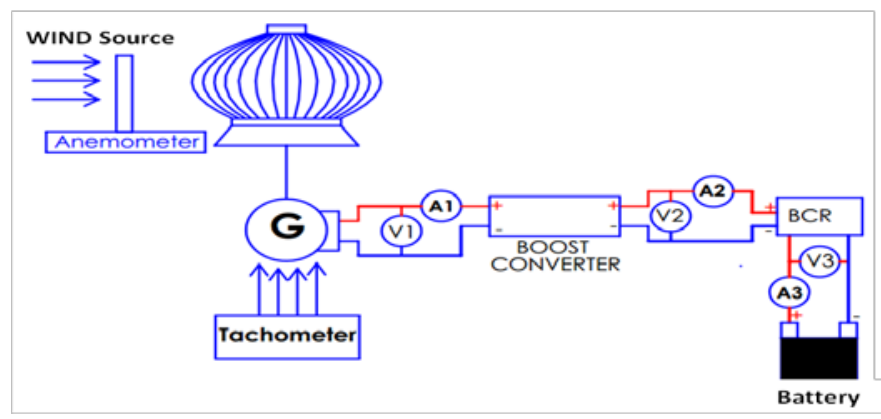

Figure 3. Electrical system diagram

\subsection{Design Testing Method}

The measurements have been carried out to obtain the values of wind speed, rotational speed of the dc generator, the input voltage to the boost converter and the current into the battery through solar regulator as the battery charge controller, as displayed in Figure 4.

The boost converter has been used to increase the generator output voltage up to certain desired value. The measurement has been undertaken on the output voltage of the generator, the generator rotation speed, the output voltage of the boost converter, as well as on the current of the boost converter.

The energy produced can be obtained by integrating the graph of power with respect to time. Based on the measurement of the generated power with certain time interval, an approach to obtained the generated energy can be obtained using the trapezoidal method [15], as displayed in Figure 5.

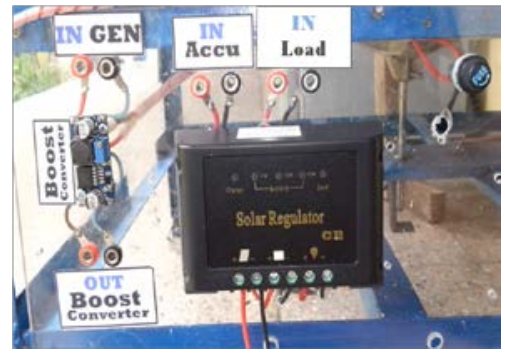

Figure 4. Testing and measurement circuit

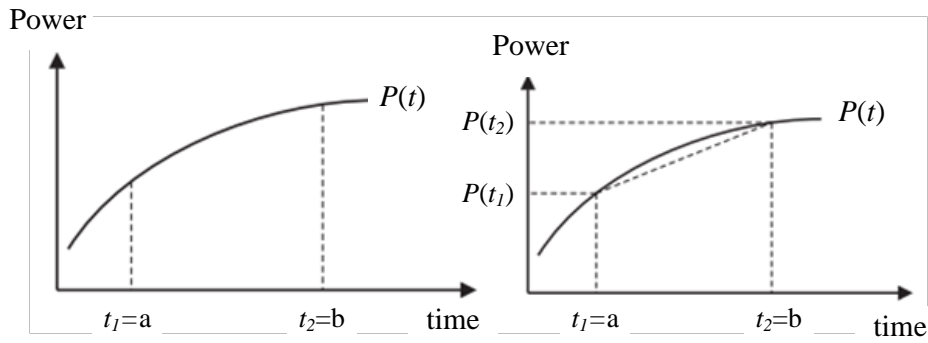

Figure 5. An approximation to calculate the energy produced during certain time interval using the trapezoidal method

As seen in Figure 5, the produced energy can be found using Equation 2.

$$
\int_{\mathrm{t}_{1}}^{\mathrm{t}_{2}} P(t) \mathrm{d} t \approx \frac{\Delta t}{2}\left[P\left(t_{1}\right)+P\left(t_{2}\right)\right]
$$

As given in Equation 2, $\Delta$ t represents the time interval between two consecutive measurements of the generated power $P$ at time $t_{1}$ and $t_{2}$. Using small value of measurement time-interval, the produced energy in watt-hours can be approximated based on the measurement of power at two consecutive times.

\subsection{Calculation of System Efficiency} equation.

The efficiency of the resulted wind-power generating system can be approached by the following

$$
\eta=\frac{\text { Generator output power }}{\text { Wind power }} \times 100 \%
$$


Using the measurement data, the generator output power can be calculated, whereas the amount of the wind power is obtained from the measurement of wind speed at a temperature of $30^{\circ} \mathrm{C}$.

\section{RESULTS AND ANALYSIS}

\subsection{System Implementation}

The variation of measurement parameters as a function of time is given in Table 1. It shows the results of system implementation testing data, including the recorded wind speed, rotation, generator voltage and current, voltage and current of boost converter, and the battery voltage and current during the battery charging.

Table 1. The measurement data of system implementation-the battery charging as a function of time

\begin{tabular}{ccccccccc}
\hline \multirow{2}{*}{ Hour } & \multirow{2}{*}{ Wind Speed $(\mathrm{m} / \mathrm{s})$} & \multicolumn{3}{c}{ Generator } & \multicolumn{2}{c}{ Boost Converter } & \multicolumn{2}{c}{ BCR Battery } \\
\cline { 2 - 8 } & & RPM & V1 $(\mathrm{V})$ & A1 $(\mathrm{A})$ & V2 $(\mathrm{V})$ & A2 $(\mathrm{A})$ & V3 $(\mathrm{V})$ & A3 $(\mathrm{A})$ \\
\hline 9:00 & 6.32 & 206 & 8.72 & 1.41 & 13.02 & 0.85 & 10.50 & 0.80 \\
$10: 00$ & 8.07 & 263 & 11.15 & 2.31 & 13.01 & 1.78 & 11.31 & 1.68 \\
$11: 00$ & 7.96 & 259 & 10.99 & 2.25 & 13.01 & 1.71 & 11.49 & 1.60 \\
$12: 00$ & 7.52 & 245 & 10.38 & 2.00 & 13.00 & 1.44 & 11.62 & 1.37 \\
$13: 00$ & 8.55 & 278 & 11.80 & 2.59 & 13.01 & 2.11 & 11.76 & 1.99 \\
$14: 00$ & 8.69 & 283 & 12.00 & 2.68 & 13.01 & 2.22 & 11.89 & 2.07 \\
$15: 00$ & 8.59 & 279 & 11.85 & 2.61 & 13.02 & 2.14 & 12.02 & 2.01 \\
$16: 00$ & 8.55 & 278 & 11.80 & 2.59 & 13.00 & 2.11 & 12.14 & 1.96 \\
$17: 00$ & 8.47 & 276 & 11.69 & 2.54 & 13.01 & 2.06 & 12.24 & 1.93 \\
$18: 00$ & 8.07 & 263 & 11.15 & 2.31 & 13.01 & 1.78 & 12.32 & 0.27 \\
$19: 00$ & 7.96 & 259 & 10.99 & 2.25 & 13.01 & 1.71 & 12.39 & 0.44 \\
$20: 00$ & 7.51 & 244 & 10.37 & 2.00 & 13.02 & 1.43 & 12.44 & 0.73 \\
$21: 00$ & 6.89 & 224 & 9.51 & 1.68 & 13.00 & 1.11 & 12.47 & 1.09 \\
$22: 00$ & 5.91 & 192 & 8.17 & 1.24 & 13.01 & 0.70 & 12.49 & 1.22 \\
$23: 00$ & 6.32 & 206 & 8.72 & 1.41 & 13.01 & 0.85 & 12.55 & 1.33 \\
$0: 00$ & 5.24 & 171 & 7.24 & 0.97 & 12.60 & 0.50 & 12.58 & 1.74 \\
$1: 00$ & 1.31 & 43 & 1.81 & 0.06 & 2.17 & 0.05 & 12.59 & 1.99 \\
$2: 00$ & 1.66 & 54 & 2.29 & 0.10 & 1.56 & 0.13 & 12.59 & 1.98 \\
$3: 00$ & 1.90 & 62 & 2.62 & 0.13 & 2.17 & 0.14 & 12.59 & 1.98 \\
$4: 00$ & 1.66 & 54 & 2.29 & 0.10 & 1.00 & 0.20 & 12.59 & 1.99 \\
$5: 00$ & 1.31 & 43 & 1.81 & 0.06 & 1.00 & 0.10 & 12.60 & 2.00 \\
$6: 00$ & 1.90 & 62 & 2.62 & 0.13 & 1.87 & 0.16 & 12.60 & 0.00 \\
$7: 00$ & 1.66 & 54 & 2.29 & 0.10 & 1.51 & 0.13 & 12.60 & 0.00 \\
$8: 00$ & 1.31 & 43 & 1.81 & 0.06 & 1.87 & 0.05 & 12.60 & 0.00 \\
\hline
\end{tabular}

As can be observed from the table, the maximum wind speed occurred at 14:00, i.e. of $8.69 \mathrm{~m} / \mathrm{s}$, which had been produced at the rotation speed of around $283 \mathrm{rpm}$, the generator voltage of $12 \mathrm{~V}$ and the battery charging current of 2.31A.

The implementation of the whole system testing has been performed to measure the wind speed during 24 hours. The testing on the battery charging has also been carried out using the lighting lamp load of 5W, $10 \mathrm{~W}$ and $15 \mathrm{~W}$.

Based on the measurement data, the output power of the generator under loading condition with respect to time can be determined, as given in Figure 6. As indicated, the generated power as a function of time indirectly represents the variation of wind speed during the whole day. During the test, the generator has been loaded with three variations of load power, namely 5W, 10W and 15W. The daily generated energy may be approximated by the trapeziodal method to integrate the power curve as a function of time. The approximated daily energy produced was 314.66Wh.

\subsection{Voltage Variations}

It is interesting to know the relationship between the voltage of generator, boost converter and the battery charging. These variations are given in Figure 7. It is clear from the figure that the charging voltage variation starting at 1:00 o'clock tends to be linear due to the wind speed condition, which was blowing slowly, resulting in small voltage values.

\subsection{Current Variations}

It is also important to know the relationship between the currents in generator and the boost converter, as shown in Figure 8. It indicates that the patterns of the current generated on the generator and boost converter are strongly influenced by the wind speed captured by the designed system. 


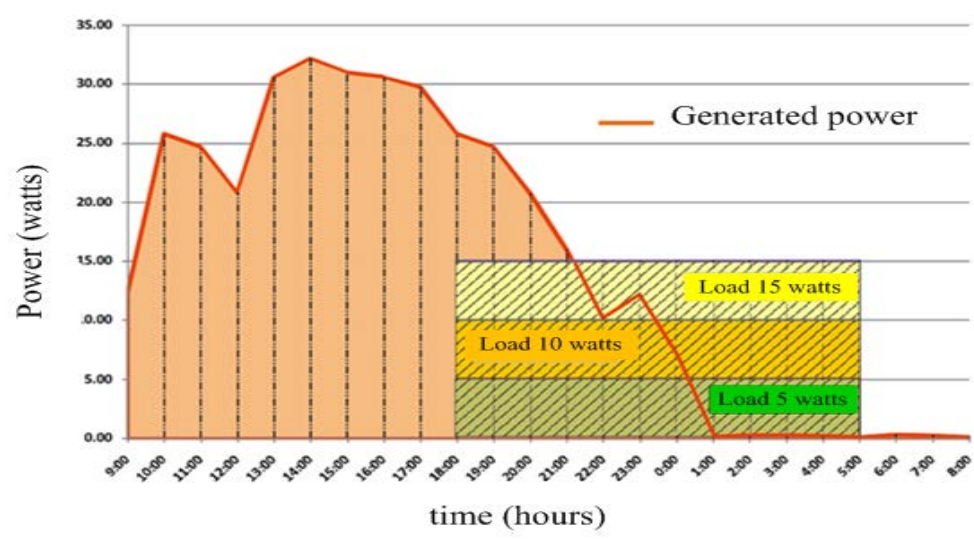

Figure 6. The generator output power as a function of time

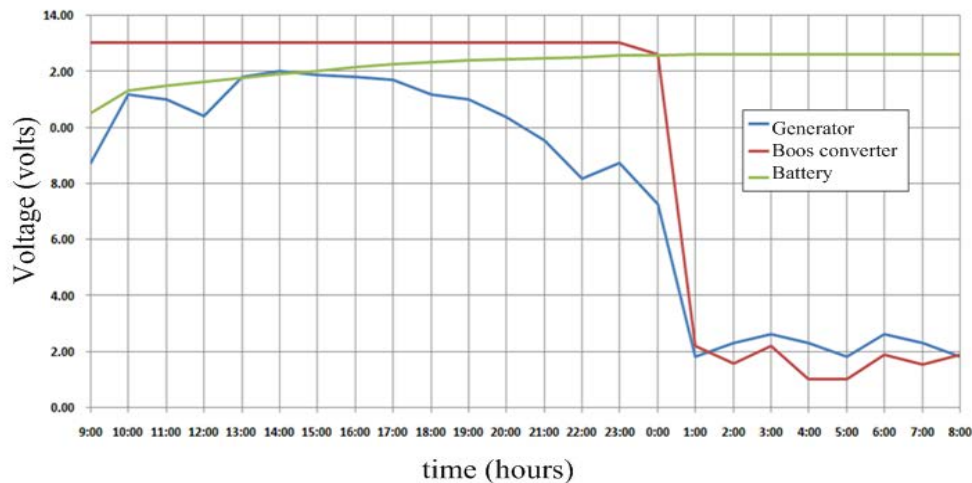

Figure 7. Voltage variations in generator, boost converter and battery

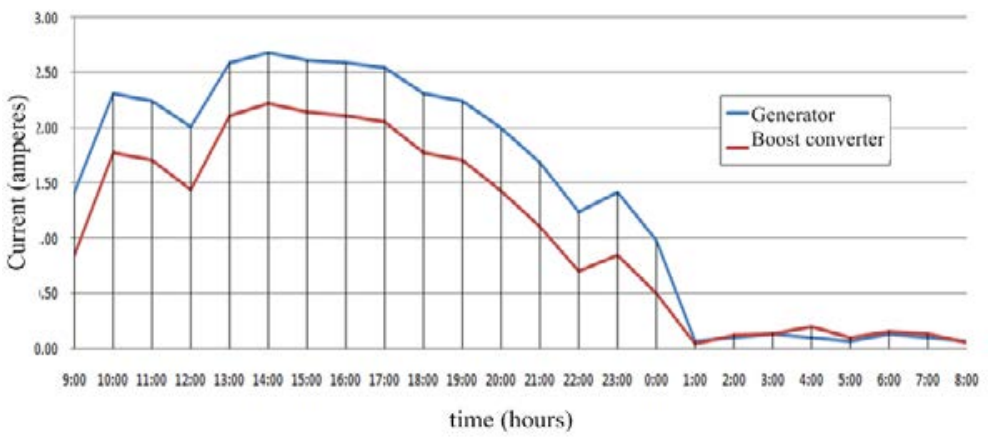

Figure 8. The current variations in generator and boost converter

A similar pattern was also obtained when the observation and measurement of the battery charging current were done, as shown in Figure 9. Figure 8 and Figure 9 clearly show the same graph patterns. The difference lies only in the values of the corresponding parameters. The highest generator current was 2.68A, the converter current was $2.19 \mathrm{~A}$, whereas the highest charging current was $2.28 \mathrm{~A}$. 


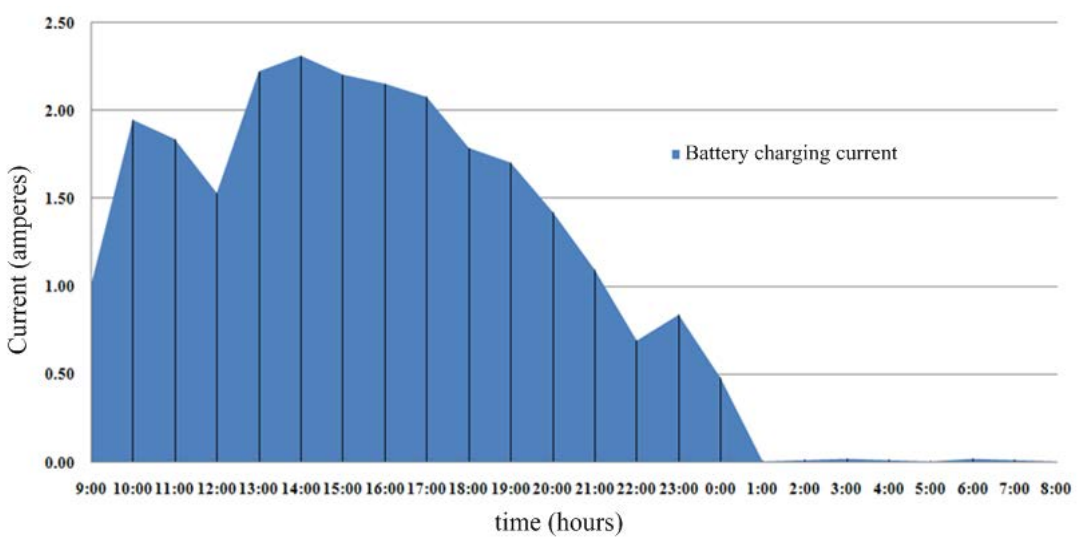

Figure 9. The variation of battery charging-current

\subsection{Battery Capacity}

The battery capacity has been tested by loading it with 3 different power capacities of LED lamps, i.e. $5 \mathrm{~W}, 10 \mathrm{~W}$ and $15 \mathrm{~W}$. The loading has been started with $100 \%$ of battery capacity, or equivalent to $12.7 \mathrm{~V}$ of the battery voltage. The remaining battery capacity measurements have been done every 1 hour and the results can be seen in Table 2 .

Table 2. The decrease in battery capacity because of loading

\begin{tabular}{ccccc}
\hline No. & Time & \multicolumn{3}{c}{ Battery Capacity } \\
& & 5 L Load & 10 Load & 15 W Lad \\
\hline 1 & $9: 00$ & $100 \%$ & $100 \%$ & $100 \%$ \\
2 & $10: 00$ & $100 \%$ & $100 \%$ & $100 \%$ \\
3 & $11: 00$ & $100 \%$ & $100 \%$ & $100 \%$ \\
4 & $12: 00$ & $100 \%$ & $100 \%$ & $100 \%$ \\
5 & $13: 00$ & $100 \%$ & $100 \%$ & $100 \%$ \\
6 & $14: 00$ & $100 \%$ & $100 \%$ & $100 \%$ \\
7 & $15: 00$ & $100 \%$ & $100 \%$ & $100 \%$ \\
8 & $16: 00$ & $100 \%$ & $100 \%$ & $100 \%$ \\
9 & $17: 00$ & $100 \%$ & $100 \%$ & $100 \%$ \\
10 & $18: 00$ & $99 \%$ & $97 \%$ & $96 \%$ \\
11 & $19: 00$ & $97 \%$ & $94 \%$ & $92 \%$ \\
12 & $20: 00$ & $96 \%$ & $92 \%$ & $88 \%$ \\
13 & $21: 00$ & $94 \%$ & $89 \%$ & $83 \%$ \\
14 & $22: 00$ & $93 \%$ & $86 \%$ & $79 \%$ \\
15 & $23: 00$ & $92 \%$ & $83 \%$ & $75 \%$ \\
16 & $0: 00$ & $90 \%$ & $81 \%$ & $71 \%$ \\
17 & $1: 00$ & $89 \%$ & $78 \%$ & $67 \%$ \\
18 & $2: 00$ & $88 \%$ & $75 \%$ & $63 \%$ \\
19 & $3: 00$ & $86 \%$ & $72 \%$ & $58 \%$ \\
20 & $4: 00$ & $85 \%$ & $69 \%$ & $54 \%$ \\
21 & $5: 00$ & $83 \%$ & $67 \%$ & $50 \%$ \\
22 & $6: 00$ & $83 \%$ & $67 \%$ & $50 \%$ \\
23 & $7: 00$ & $83 \%$ & $67 \%$ & $50 \%$ \\
24 & $8: 00$ & $83 \%$ & $67 \%$ & $50 \%$ \\
\hline
\end{tabular}

Based on the observation on Table 2, it appears that within 24 hours the battery capacity decreased to $83 \%$ or $12.45 \mathrm{~V}$ for $5 \mathrm{~W}$ load, $67 \%$ for $10 \mathrm{~W}$ and $50 \%$ for $15 \mathrm{~W}$ respectively. Graphically, it is described in Figure 10. The figure proves that greater the load on the battery, faster the battery capacity decreases.

\subsection{System Efficiency}

Before determining the efficiency of the system, the potentially generated wind power should be calculated based on the wind speed measurement results. The relationship between the wind speed and the power generated can be seen in Figure 11.

After determining the generated wind power, the output power of the generator can be obtained. Finally, the efficiency of the system can be found. The relationship between the wind speed and system efficiency is shown in Figure 12. 


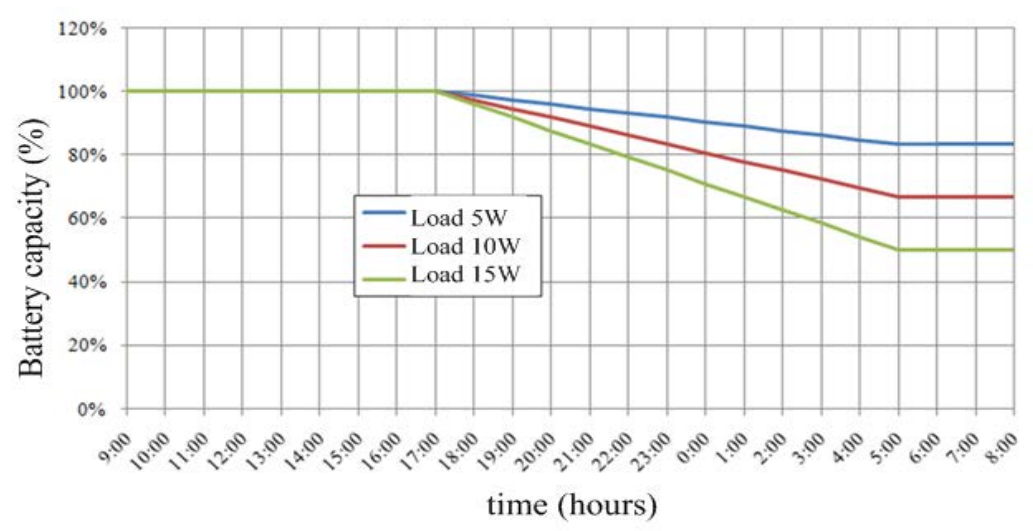

Figure 10. The decrease of battery capacity because of loading

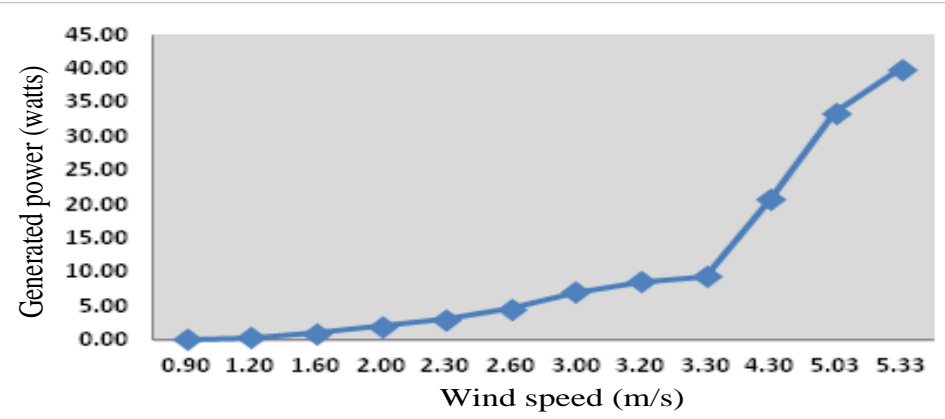

Figure 11. Wind power as a function of wind speed

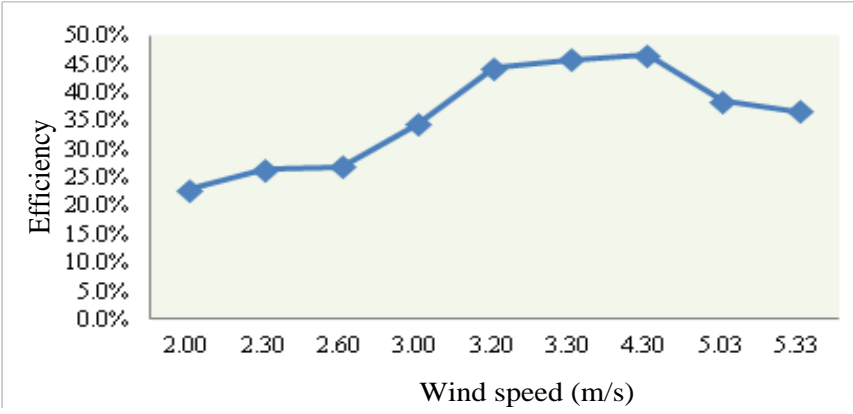

Figure 12. System efficiency as a function of wind speed

Figure 12 indicates that the system efficiency rises drastically at wind speeds of $2-3.5 \mathrm{~m} / \mathrm{s}$. The maximum efficiency of $46.6 \%$ has been obtained at a speed of $4.3 \mathrm{~m} / \mathrm{s}$. Beyond this speed the efficiency tends to decrease. This fact shows that during the executed experimentation the optimum tip speed ratio or maximum power coefficient occurs during wind speed of $4.3 \mathrm{~m} / \mathrm{s}$. Through this, the rotational speed should be identified during this wind speed measurement, and hence, the optimum generator speed could be determined for this cyclone-turbine.

\section{CONCLUSION}

The designed cyclone-turbine model presented in this paper could be used to extract energy from the rooftop ventilator. The addition of extra fins on the turbine blades has been used with the aim to increase the speed and the area of the rotor sweep area, and consequently the captured energy. 
The cyclone turbine specification used in this study was capable of working well at certain maximum wind speed, resulting in the best system efficiency and being determined by the design.

The variation of current values as a function of time on the generator, boost converter and during the battery charging indicated the same graph pattern. The difference was only in the values of the corresponding parameters.

The reduction of the battery capacity is determined by the load power used. Higher the power of the load, faster will be the battery capacity reduction.

\section{REFERENCES}

[1] Dangeam S. An Electric Generator Driven by a Roof Ventilator. Energy Procedia. 2011; 9: 147-158.

[2] Suresh A, Jacob B, Sharaf LF, Gomathy S. Development of Micropower Generation System Using Rooftop Ventilator. IOSR Journal of Electrical \& Electronics Engineering (IOSR-JEEE). 2017; 88-91.

[3] Daud I, Shatri C, Irwanto M, Syafawati AN, Shema SS. Power Generation Roof Ventilator. International Conference on Environment and Industrial Innovation, IPCBEE. Singapore. 2011; 12: 183-187.

[4] Bhutta MMA, Hayat N, Farooq AU, Ali Z, Jamil SR, Hussain Z. Vertical Axis Wind Turbine - A Review of Various Configurations and Design Techniques. Renewable \& Sustainable Energy Reviews. 2012; 16: 1926-1939.

[5] Eriksson S, Bernhoff H, Leijon M. Evaluation of Different Turbine Concepts for Wind Power. Renewable \& Sustainable Energy Reviews. 2008; 12(5): 1419-1434.

[6] Wibawa U, Utomo T. Impacts of exhaust airflow velocity to electrical power generation of small wind energy conversion system (WECS). IEEE 2014 Electrical Power, Electronics, Communicatons, Control and Informatics Seminar (EECCIS). Malang. 2014: 16 - 22.

[7] Shun S, Ahmed NA. Utilizing Wind and Solar Energy as a Power Sources for Hybrid Building Ventilation Device. J. Renewable Energy. 2008; 33: 1392 - 1397.

[8] Kaewtip P, Hoonchareon N. A Magnetic Levitation Rooftop Turbine Ventilator: A Case Study for Wind Micro Generation. International Journal of Innovative Research \& Science, Engineering and Technology. 2012; 3: 11425 $-11434$.

[9] Torasa C, Sermsri N. The Application of Roof Ventilator for Electricity Generation. Procedia-Social and Behavioural Science. 2015; 197: 1690-1696.

[10] Wagner HJ, Mathur J. Introduction to Wind Energy Systems: Basic, Technology, and Operation. Germany: Springer, 2009.

[11] Masri S, Chan PW. Design and Development of A DC-DC Boost Converter with Constant Ouput Voltage. IEEE 2010 International Conference on Intelligent and Advance System. Kuala Lumpur, Malaysia. 2011: 1-4.

[12] Huang Y, Qi J. Hydraulic Motor Driving Variable-Pitch System for Wind Turbine. TELKOMNIKA Indonesian Journal of Electrical Engineering. 2013; 11(11): 6540-6546.

[13] Prashanth NA, Sujatha P. Commonly used Wind Generator Systems: A Comparison Note. Indonesian Journal of Electrical Engineering and Computer Science (IJEECS). 2017; 7(2): 299-311.

[14] Petinrin J.O., Agbolade J.O., Shaaban M. Voltage Regulation in a Microgrid with Hybrid PV/Wind Energy. TELKOMNIKA Indonesian Journal of Electrical Engineering. 2015; 14(3): 402-409.

[15] Eba Flora E, Lakshmi P, Sunithamani S. Simulation of MEM Energy Harvester with Different Geometries and Cross Sections. 2013 IEEE International Conference on ICT. Thuckalay, Tamil Nadu, India, India. 2013: 120-123. 